\title{
A PERCEPÇÃO DO PROFESSOR SOBRE SUAS COMPETÊNCIAS EM TECNOLOGIAS DA INFORMAÇÃO E COMUNICAÇÃO
}

Vera Rejane Niedersberg Schuhmacher - vera.schuhmacher@ unisul.br-UNISUL Elcio Schuhmacher - Depto. Física, FURB - elcio@ furb.br

Lia Raquel M. Oliveira - Instituto de Educação, UMINHO - lia@ ie.uminho.pt Clara Pereira Coutinho - Instituto de Educação, UMINHO - ccoutinho@ie.uminho.pt

Resumo: A inserção das tecnologias da informação e comunicação - TIC no Ensino Superior vem sendo apontada como uma certeza na prática docente de professores. É pouco, no entanto, o que se sabe sobre como tal inserção vem ocorrendo e como o formador percebe as competências necessárias para seu uso e apropriação no processo de ensino e aprendizagem. Este artigo relata os resultados da investigação realizada com professores do Ensino Superior da Universidade do Minho - Portugal em que se perscrutou a percepção do professor acerca de suas competências em TIC, motivações e potencialidades que o mobilizam para esta inserção. A pesquisa mista (qualitativa e quantitativo) fez uso da técnica de questionário e da análise categorial para a análise dos registros. Os resultados se estruturam apresentando um professor que acredita na inserção curricular das TIC e em suas potencialidades, mas a introdução em sua prática se faz presente de forma operacional denotando a carência de competências didáticopedagógicas na integração das TIC.

Palavras-chave: Tecnologia da informação e comunicação; ensino superior; professor formador.

\section{THE TEACHERS PERCEPTION OF THEIR SKILLS IN INFORMATION AND COMMUNICATION TECHNOLOGIES}

Abstract: The integration of information and communication technologies - ICT in higher education has been identified as a certainty in the teaching practice of teachers. It is little, however, what is known about how such insertion is happening and how the teacher perceives the skills required for their use and ownership in the process of teaching and learning. This article reports the results of research conducted with Higher Education professors from the University of Minho - Portugal in which scanned the perception of the teacher about their ICT skills, motivations and capabilities that mobilize for this insertion. The joint research (qualitative and quantitative) took the questionnaire technique and the categorical analysis to examine the records. The results are structured having a teacher who believes in curricular integration of ICT and its potential, but the introduction into their practice is present operationally denoting the lack of didactic and pedagogical skills in integrating ICT.

Key words: information and communication technology; higher education; teacher trainer.

\section{Introdução}

As Tecnologias da Informação e Comunicação se encontram cada vez mais embebidas em nossa sociedade. Castells (2002) observa que vivemos em uma sociedade na qual a maciça inserção tecnológica transforma a forma como o ser humano gera e convive com o conhecimento.

A revolução tecnológica traz fortes demandas para a Educação, julga-se que as TIC enriquecem o processo de ensino-aprendizagem quando propiciam a criação de condições para a construção e apropriação de conhecimentos, habilidades e atitudes. Estes passam 
a fazer sentido à medida que os conteúdos são abordados (Schuhmacher e Pinho (2013); Coutinho e Bottentuit Junior (2008)).

As exigências e reivindicações sobre a qualidade da educação e, por consequência, sobre a formação de educadores trazem para a discussão a inserção curricular das TIC na formação de professores e a literacia digital dos formadores. O professor tem um papel central na inserção curricular das TIC, pois é ele o responsável pela ressignificação do emprego dessa em suas práticas, e que por sua vez, é dependente das competências que este possui para mobilizar tais conhecimentos. Para que ocorra a integração das TIC no ensino desafia-se o professor em competências múltiplas que muitas vezes ultrapassam a sua familiaridade no uso eficiente de seus recursos:

A adequada integração das TIC em sala de aula dependerá da habilidade dos professores em estruturar o ambiente de aprendizagem de modo não-tradicional; em fundir a nova tecnologia com a nova pedagogia [...] (Unesco, 2008, p.9).

Neste contexto há de se refletir se as competências necessárias a inserção curricular das TIC como objeto de mediação, estudo e pesquisa se fazem presentes no perfil profissional do professor formador.

Este artigo apresenta os resultados da investigação com professores do Ensino Superior da Universidade do Minho - Portugal que teve por objetivo identificar, na perspectiva docente, as competências que o professor entende possuir em TIC, as potencialidades e motivações que o impulsionam a promover esta inserção na prática em sala de aula.

\section{Competência docente em TIC}

A definição de competências necessárias ao docente do século XXI tem sido tema de pesquisas em todo o mundo. Em 2008, a UNESCO lançou o projeto "Padrões de Competências em TIC para professores". O relatório indica a demanda de novos saberes, para que o professor faça frente às novas tecnologias no contexto educacional. O projeto se concentra nos professores de escolas primárias e secundárias, embora possa ser aplicado a todos os níveis de ensino. Dentre as capacidades exigidas do professor, o documento ressalta o desenvolvimento de formas inovadoras de usar a tecnologia para melhorar o ambiente de aprendizagem. O professor deve ser capaz de "[...] incentivar a alfabetização em tecnologia, o aprofundamento do conhecimento e a criação do conhecimento"(UNESCO, 2008, p.9).

Segundo Schuhmacher (2014) nesse contexto, o professor deve adquirir competências que lhe permitam oportunizar aos alunos a aprendizagem com apoio da tecnologia. Para tanto, deve estar preparado para utilizá-la bem como ser capaz de reconhecer como esta pode ser utilizada no apoio ao aprendizado. $\mathrm{O}$ uso das TIC pelo docente não se resume à aprendizagem de um determinado aplicativo, mas em encontrar formas produtivas e viáveis de integrá-las ao processo de ensino-aprendizagem à luz da estrutura curricular e da identidade e contexto de cada escola.

O professor deve ser um explorador capaz de perceber o que lhe pode interessar, e de aprender, por si só ou em conjunto com colegas, a tirar partido das respectivas potencialidades. O professor passa a estar em um estado de sempre aprender, deixa de ser a autoridade incontestada do saber. O Livro Verde da Sociedade da Informação de Portugal registra a importância do professor neste universo tecnológico que adentra as escolas:

O desenvolvimento das novas tecnologias não diminui em nada o papel dos professores antes o modifica profundamente, [...] Torna-se, de algum modo, parceiro de um saber coletivo que lhe compete organizar 
[...]. Há, pois, que elaborar conteúdos programáticos que façam com que estas tecnologias se tornem verdadeiros instrumentos de ensino, o que pressupõe, da parte dos professores, vontade de questionar as suas práticas pedagógicas [...] (Livro Verde, 1997, p. 42).

Em 2008 foi apresentado o "Estudo de Implementação em Competências TIC para Portugal" desenvolvido no âmbito do Plano Tecnológico da Educação sendo norteador para a capacitação dos professores, em questões relacionadas a inovação das práticas pedagógicas, de forma integrada às TIC. No estudo foram estabelecidas as competências desejadas em TIC para diferentes atores do sistema escolar, entre estes, o professor do $2^{\circ}$ e $3^{\circ}$ ciclo do Ensino Básico e do Ensino Secundário. Embora não tenha sido desenvolvido com uma proposta de formação contínua e de certificação de competências em TIC para o Ensino Superior, o documento reforça as ações necessárias para o professor formador.

As competências sugeridas ao professores envolvem o conhecimento atualizado dos recursos tecnológicos e suas potencialidades no ensino; competências em operações relacionadas ao hardware; informações digitais; comunicação; aplicativos; uso de software para desenvolvimento de documentos digitais para suporte de processos de avaliação e/ou de investigação; uso dos recursos digitais na promoção do seu próprio desenvolvimento profissional numa perspectiva de aprendizagem ao longo da vida (Costa, 2008).

O modelo estabelece 3 certificações integradoras para a formação dos professores sendo elas: 1- certificado de competências digitais; 2- certificado de competências pedagógicas com TIC; 3 - certificado com competências pedagógicas com TIC ( Costa, 2008).

Segundo Costa (2008) a adoção das TIC pelo professor não determina mudanças pedagógicas, no entanto, as concepções pedagógicas dos professores influenciam a inserção das TIC na prática em sala de aula. A carência da concepção pedagógica parece levar o professor a inserir as TIC em sua prática a partir de uma utilização semelhante ao que fazia e como fazia com a tecnologia anterior (Cuban, 1993). Em diferentes estudos tem-se a reflexão de que as TIC na prática docente do Ensino Superior se apresentam em tarefas pouco exigentes do ponto de vista cognitivo e por vezes apenas inseridas em situações de uso operacional (Silva et al., 2014; Gomes, Amante e Oliveira, 2012; Schuhmacher (2014)).

Em Portugal a preocupação com a inserção das TIC de forma curricular é tema de debates entre pesquisadores e de políticas públicas que visam garantir de forma adequada sua integração em atividades educacionais. Mas ainda parecem tímidas as premissas que estabelecem as prerrogativas de competências necessárias para o Ensino Superior:

Verifica-se igualmente a inexistência de referenciais de competências digitais que enquadrem a prática profissional docente no ensino superior português, bem como a ausência de estudos caracterizadores das competências digitais deste público e/ou das suas necessidades formativas neste domínio (Lemos e Pedro, 2012, p. 2840).

Tendo em vista a carência de fontes portuguesas sobre as competências em TIC desejáveis ao professor do Ensino Superior aduzimos o projeto EA2009-0122 da Secretária de Estado de Universidades em que são relatados os resultados do estudo sobre as competências em TIC de professores da Universidade Pública Espanhola. No desenvolvimento do estudo foi proposto um modelo organizacional de competências digitais para professores universitários. Segundo Prendes (2010) o modelo está estruturado em torno de três áreas principais que coincidem com as três áreas básicas nas quais invariavelmente se compreende a área de atuação do professor no Ensino Superior: 
docência (D), a investigação (I) e a gestão (G). As competências em TIC dos professores para cada uma das áreas está alicerçada em três níveis de proficiência cumulativos.

No nível de domínio 1 proposto em Prendes (2010) as competências compreendem bases de conhecimento subjacentes à utilização das TIC. No segundo nível são abarcadas competências precisas para design, implementação e avaliação de ações com TIC. O nível de domínio 3 introduz competências como a análise reflexiva e crítica sobre a ação realizada com as TIC, individualmente ou em contextos coletivos.

Entende-se no modelo que um professor deve ter as habilidades de um nível para desenvolver adequadamente o próximo nível. O modelo inclui indicadores, em áreas de desempenho concretas, para cada um dos níveis de domínio.

\section{Percurso Metodológico}

A natureza da pesquisa envolve a recolha e tratamento de dados de ordem qualitativa e quantitativa. Para realizar a investigação elegeu-se a técnica de inquérito por questionário. Inicialmente, realizou-se à elaboração de um quadro matriz, no qual foram listadas as dimensões, objetivos e as respectivas questões. O Quadro 1 expõe o planejamento para a elaboração do instrumento:

\section{Quadro 1. Matriz do Questionário Professores Ensino Superior}

\begin{tabular}{|c|c|c|}
\hline Objetivos & Questões & Escala \\
\hline \multicolumn{3}{|l|}{ Dimensão: Literacia em TIC } \\
\hline Conhecer o tempo que o docente faz uso das TIC no Ensino. & 1 & \\
\hline Identificar a origem dos conhecimentos docentes em TIC. & 4 & \\
\hline Averiguar as competências que o docente possui em TIC. & 3 & \\
\hline \multicolumn{3}{|l|}{ Dimensão: As TIC na prática docente } \\
\hline Identificar a frequência de uso da TIC na prática docente. & 5 & $\begin{array}{l}\text { Sempre; Frequentemente; } \\
\text { Raramente, Nunca. }\end{array}$ \\
\hline Identificar o tipo de uso dado às TIC na prática docente. & 5 & \\
\hline $\begin{array}{l}\text { Averiguar práticas em que o docente faz uso das TIC como } \\
\text { recurso de mediação. }\end{array}$ & 2 & \\
\hline \multicolumn{3}{|l|}{ Dimensão: Os obstáculos no uso das TIC em sala da aula } \\
\hline $\begin{array}{l}\text { Investigar as situações entendidas como obstáculos ao uso } \\
\text { das TIC em sua prática pelo docente. }\end{array}$ & 16 & $\begin{array}{l}\text { Obstáculo Forte; Médio; } \\
\text { Fraco; Não é Obstáculo. }\end{array}$ \\
\hline $\begin{array}{l}\text { Averiguar os sentimentos sobre o uso das TIC na prática } \\
\text { docente. }\end{array}$ & 13 & $\begin{array}{l}\text { Concordo:Completamente; } \\
\text { Parcialmente; Discordo: } \\
\text { Parcialmente; } \\
\text { Completamente; Sem } \\
\text { Opinião; Discordo. }\end{array}$ \\
\hline \multicolumn{3}{|l|}{ Dimensão: Motivação para inserção das TIC na prática docente } \\
\hline $\begin{array}{l}\text { Identificar como o docente percebe as contribuições das } \\
\text { TIC em sua prática. }\end{array}$ & 13 & \\
\hline Conhecer as motivações que o levaram a fazer uso das TIC . & 12 & \\
\hline \multicolumn{3}{|l|}{ Dimensão: Identificação do professor } \\
\hline Conhecer a formação do docente. & 2 & \\
\hline Conhecer a faixa etária do professor. & 1 & \\
\hline Conhecer a atuação profissional do professor no Ensino. & 2 & \\
\hline
\end{tabular}

$\mathrm{O}$ instrumento foi submetido a um processo de validação, com o intuito de "garantir a qualidade dos resultados da investigação no sentido de podermos aceitá-los como fatos indiscutíveis" (Coutinho, 2011, p. 110).

A validação foi realizada antes da aplicação do questionário em duas etapas. $\mathrm{Na}$ primeira etapa realizou-se uma validação semântica em que se teve como propósito: aevitar que um enunciado ou assertiva pudesse ter mais de uma interpretação; b- eliminar inconsistências relacionadas a linguagem utilizada no instrumento. Tal ação visa 
aproximar os enunciados e assertivas da linguagem dos respondentes evitando falsas interpretações e situações de hesitação ou insegurança durante seu preenchimento. Desse processo fizeram parte 5 indivíduos, todos professores do Ensino Superior, sendo estes 2 especialistas em Educação e 3 possíveis respondentes.

$\mathrm{Na}$ segunda etapa realizou-se a validação de conteúdo sobre a matriz de especificações, em que, foram operacionalizadas as definições dos construtos que os ítens devem abranger, conforme sugerido por Almeida e Freire (1997 como citado em Coutinho, 2011, p. 124). A validação foi realizada por 2 especialistas em Educação, em que estes, teceram opiniões, críticas e sugestões para melhoria do instrumento e adequação aos construtos.

O instrumento foi composto por 79 questões. O questionário contempla questões abertas (05) e fechadas (74) que buscam obter dados satisfatórios às questões e aos objetivos propostos na investigação.

$\mathrm{O}$ instrumento foi desenvolvido de forma on-line, por meio do aplicativo Formulários Google e aplicado, em sua primeira fase, a docentes da Universidade do Minho. A Universidade concentra sua sede na cidade de Braga, no Largo do Paço, dispondo de dois polos Universitários em Gualtar (Braga) e Azurém (Guimarães). A Instituição conta com 1.208 professores universitários (Cunha, 2014).

$\mathrm{O}$ inquérito teve sua primeira aplicação no período de 28 de setembro a 12 de outubro de 2015. Os professores foram convidados a tomar parte no inquérito a partir de envio de $e$-mail em cujo teor descreveu-se de forma breve o objetivo da investigação. Foi utilizado para o convite o e-mail institucional por grupos de área. No primeiro período foram coletados 37 inquéritos respondidos de forma completa. Realizou-se então um segundo reforço por meio de mensagem de $e$-mail destacando a importância da pesquisa e da contribuição do professor. O segundo convite foi enviado em 13 de outubro de 2015 encerrando-se o segundo período de survay em 28/10/2015 com 56 inquéritos considerados válidos.

Para a análise qualitativa dos registros, definiram-se 3 categorias:

- Conhecimento em TIC - a categoria aponta para o conhecimento em TIC, sua origem, a capacidade que o professor possui de compreender uma situação de uso das TIC em sua prática, avaliando a melhor forma de reagir.

- Obstáculo estrutural - referenciados em Schuhmacher (2014).

- Obstáculo didático - referenciados em Brosseau (1976).

O artigo apresenta os resultados da análise da categoria conhecimento em TIC.

Ao nos defrontar com os resultados da análise fomos instigados pela curiosidade científica a uma nova análise: a adequação das competências do professor em relação a proposta apresentada em Prendes (2010). Assim, foram analisadas 3 das dimensões do questionário (1- Literacia em TIC; 2- a TIC na prática docente; 4- Motivação docente) quanto ao alcance das competências propostas em Prendes (2010).

\section{Discussão e Apresentação dos Dados}

A compreensão das percepções do professor sobre as TIC na prática docente está vinculada a importância de identificar o sujeito desta investigação: o docente. Assim entende-se que conhecer sua formação, sua faixa etária e atuação profissional são construtores fundamentais dessa análise.

A área científica de formação de base dos professores participantes do inquérito se distribui nas seguintes áreas de conhecimento: 2\% Ciências e Saúde; 10\% Ciências Exatas e da Terra; 23\% Ciências Humanas; 10\% Ciências Sociais e Aplicadas e 11\% Linguística, Letras e Artes. 
Os professores são em sua maioria experientes na prática docente no Ensino Superior tendo $43 \%$ mais de 20 anos e $34 \%$ entre 15 e 20 anos de experiência. A atuação docente de $35,7 \%$ dos professores acontece em cursos da área de Ciências Humanas, 28,6\% em cursos de Ciências Sociais Aplicadas, 19,6 \% em cursos de Ciências Exatas e da Terra e 8,9\% em cursos de Ciências da Saúde. Ainda, 26,8\% afirmam lecionar em disciplinas de Doutorado.

Quando questionados sobre a origem das suas competências em TIC 89,3\% afirmam ser autodidatas e $60 \%$ relatam ter solicitado a ajuda de colegas de trabalho.

O questionário também tratou questões relacionadas a inserção curricular das TIC em seus cursos de formação inicial. Ao serem questionados sobre o foco das disciplinas de formação específica para o uso das TIC em sua formação básica 19,6\% apontou o ensino do uso de softwares de produção como editores de texto, planilhas, linguagens de programação. Para 16,1\% dos questionados o curso de formação inicial apresentou disciplinas que exploraram as possibilidades do uso das TIC no desenvolvimento de práticas educacionais em sala. Contudo mais da metade dos professores da amostra (61\%) não tiveram disciplinas em sua formação que contemplassem o conhecimento em TIC. O percentual de docentes que teve inserções durante a prática do professor como um recurso de mediação não chega a $9 \%$. Em um segundo questionamento foram solicitados a refletir se a inserção das TIC durante sua formação lhe garantiu o desenvolvimento de competências, para o uso em sua prática docente, 20,4\% considera que sim. Mas 27,8\% consideram que seu curso não deu conta de promover o conhecimento necessário sobre as práticas pedagógico didáticas atreladas a inserção das TIC. Apenas 26,8\% dos professores assinalam ter participado em cursos de formação continuada oferecidos pela Instituição onde lecionam.

Quanto ao domínio dos recursos tecnológicos e seus recursos 59\% consideram que são sólidos e 37,5\% identificam possuir conhecimento mediano. Apenas 3,5\% consideram insuficiente o conhecimento para realizar seu uso na prática docente.

Foi solicitado ao professor a indicação sobre a frequência de uso das TIC em sua prática a partir de situações predeterminadas. O resultado aponta que quase $100 \%$ dos professores usam os recursos das TIC sempre ou frequentemente na preparação de materiais para suas aulas. A discussão que pode ser promovida por meio de recursos como fóruns, chat's, blogs entre outros é ainda pouco incorporada, 68\% dos docentes mencionam ser raro ou nunca usar este recurso. Os repositórios atendem a maioria dos professores, plataformas disponibilizadas pela Instituição como a Blackboard são efetivamente usadas para disponibilização de materiais por $100 \%$ dos professores. Isto também é corrobado no relato do professor em questões abertas:

Comunicação com os alunos (Professor-29).

$\mathrm{Na}$ comunicação com os estudantes e disponibilização dos conteúdos (Professor-51).

As TIC sendo usadas como recursos de mediação na prática de componentes curriculares é usada raramente ou nunca é usada por um quarto dos professores. Mas o relato das questões abertas também permite perceber a valorização das TIC e sua riqueza no processo de mediação quando incorporado pelo professor:

No início do ano peço aos alunos que façam perguntas acerca do uso educativo das TIC; depois escolho as que me parecem mais desafiantes; coloco uma de 15 em 15 dias no fórum da Blackboard; os alunos respondem e interagimos todos; nesta discussão entram os conteúdos curriculares que foram ou estão a ser trabalhados (Professor-52). 
Não obstante, a questão também apresenta o relato de professores que negam o uso das TIC em sua prática:

Não tenho preocupações a esse nível. Não acho necessário fazer uso (Professor-43).

A quarta dimensão do questionário teve o objetivo de identificar o que leva o professor a fazer uso das TIC a partir de duas premissas: motivação e potencialidades percebidas pelo docente. A motivação no aprendizado é vista como sua maior potencialidade por $78,6 \%$ dos professores. Com valores médios de $73,6 \%$ os professores percebem as TIC como um reforço para atividades de pesquisa, recolha e seleção de informação. Dois terços dos professores consideram as TIC como um elemento que potencializa a aprendizagem autodirigida, o aprendizado autônomo e a inclusão digital do aluno. Mas não chega a metade dos professores (44\%) os que consideram as TIC um recurso potencializador para o desenvolvimento de habilidades colaborativas, de comunicação, interdisciplinaridade, discussão, resolução de problemas e atividades exploratórias. Os professores também se posicionaram, a partir da opção aberta outros, acerca do entendimento de não haver aí um potencializador para ações em sua prática conforme transcrição abaixo:

Uso pouco as TIC, por isso não sei avaliar bem as suas potencialidades (Professor-40).

Já, o que motiva o professor do Ensino Superior a fazer uso das TIC trouxe resultados diversos para este grupo de professores a partir das possibilidades sugeridas conforme apresentado no Quadro 2. Os motivadores mais apontados relacionam-se a melhoria da organização do trabalho em sala de aula e a disseminação de materiais relacionados as atividades curriculares. Estes dados confirmam os dados apresentados sobre o tipo e frequência de uso das TIC em suas atividades docentes. Mas para além desta investigação, pontuam novamente a percepção existente no meio docente sobre a aplicabilidade das TIC no ensino.

Quadro 2- Motivadores que levam o docente ao uso das TIC no processo de ensino

\begin{tabular}{|l|c|}
\multicolumn{1}{|c|}{ Afirmativa } & $\begin{array}{c}\text { \% } \\
\text { Professor }\end{array}$ \\
\hline A existência de softwares interessantes que podem apoiar a prática pedagógica. & 57,1 \\
\hline A melhoria da organização do trabalho em sala de aula. & 67,9 \\
\hline O apoio oferecido no acompanhamento de grupos. & 33,9 \\
\hline Os projetos de pesquisa desenvolvidos na Universidade. & 25,0 \\
\hline O aprimoramento das relações entre aluno e professor. & 33,9 \\
\hline A curiosidade e o gosto por novas tecnologias. & 41,1 \\
\hline As TIC como um meio de mediação no ensino de componentes curriculares. & 50,0 \\
\hline A possibilidade de realizar atividades de discussão. & 26,8 \\
\hline A melhoria na comunicação com o aluno. & 53,6 \\
\hline A disseminação de materiais relacionadas as atividades curriculares. & 76,8 \\
\hline
\end{tabular}

Aspectos importantes no processo de ensino-aprendizagem e cujos recursos oferecidos pelas novas tecnologias favorecem não parecem motivar o professor, no caso o uso em atividades de discussão e acompanhamento de atividades em grupo. Apesar de se tratar da docência no Ensino Superior a motivação advinda do entendimento das TIC, como um objeto de pesquisa, está presente em apenas um quarto dos docentes do inquérito. Um motivador consistente, com os resultados apresentados em Schuhmacher (2014), é a de que o gosto por novas tecnologias e a curiosidade do docente em relação a estas, trazem motivação e incentivo para sua descoberta e entendimento. 
Questionados sobre os obstáculos que percebem no uso das TIC em sua Instituição de ensino, apontam que ainda é um problema a ser resolvido o acesso a internet relatado por $71,4 \%$ dos professores. Os problemas com computadores que não funcionam nos laboratórios foram indicados por $68 \%$ dos docentes. A inexistência ou demora de apoio e suporte técnico para dirimir problemas que venham a ocorrer com o hardware ou o software foi considerado por $38 \%$ como um forte obstáculo.

Com a intenção de perscrutar a percepção do professor quanto ao uso das TIC no ensino direcionou-se questionamentos acerca de sentimentos quando considerada a inserção das TIC em sua prática. O entendimento para tal, é de que os sentimentos como insegurança, desconforto, negação sejam indicativos de obstáculos que desencadeiam atitudes que impeçam ou dificultem a inserção das TIC por parte do docente.

Sabe-se que, ao longo de sua vida e de suas vivências, o professor desenvolve sentimentos, emoções que povoam seu dia a dia profissional e pessoal. Os sentimentos atuam decisivamente nas escolhas que o professor faz, determinando o que usar, como usar, porque usar, onde quer chegar e quando em sua trajetória profissional (Schuhmacher, 2014, p. 233).

Ao serem solicitados sobre se possuem sentimentos como desconforto ou insegurança quanto ao uso do computador como um recurso pedagógico ou ainda possíveis mudanças em sua prática pedagógica, mais de $50 \%$ dos professores entendem que tais situações não se configuram como um obstáculo em sua prática. Estes resultados se apresentam adversos quando comparados a pesquisas realizadas em outros países, que as apontam como a maior dificuldade para o professor e, um dos gatilhos importantes para a negação do uso das TIC em sua prática (Schuhmacher, 2014). Mas a insegurança quanto ao conhecimento técnico (uso do computador e manipulação do software) para fazer uso do recurso computacional no ensino é tida por $10,7 \%$ dos professores como um obstáculo forte e $21,4 \%$ o consideram médio.

A percepção positiva ou negativa do professor sobre a inserção das TIC em sua prática foi ponderada por questões que identificam seu sentimento em situações específicas. Os resultados apontados no Quadro 3 assinalam um professor que percebe o computador como um recurso estimulante para a prática em sala de aula, metade dos professores discordam completamente da afirmativa de que a TIC possa ser uma distração para o aluno. Mas 28,6\% concordam parcialmente de que se tem dado demasiada importância às TIC no ensino.

Quadro 3- Percepção docente sobre as TIC no processo de ensino

\begin{tabular}{|l|c|c|c|c|}
\hline \multicolumn{1}{|c}{ Afirmativa } & \multicolumn{3}{c|}{ \% Professor } \\
\cline { 2 - 4 } & \multicolumn{2}{c|}{ Concordo } & \multicolumn{2}{c|}{ Discordo } \\
\cline { 2 - 4 } & Comp & Parc & Comp & Parc \\
\hline Sou indiferente quanto ao uso das TIC no Ensino. & 1,8 & 7,1 & 30,4 & 62,5 \\
\hline Não acredito que o uso das TIC possa contribuir na prática docente. & 1,8 & 3,6 & 26,8 & 67,9 \\
\hline O uso do computador em sala de aula é uma distração. & 5,4 & 12,5 & 32,1 & 51,8 \\
\hline O uso do computador tira o foco do conteúdo da disciplina. & 1,8 & 14,3 & 28,6 & 55,4 \\
\hline Trabalhar com o computador em sala de aula é estimulante. & 32,1 & 53,6 & 12,5 & 3,6 \\
\hline Preocupa-me a importância demasiada dada às TIC no ensino. & 8,9 & 28,6 & 30,4 & 33,9 \\
\hline $\begin{array}{l}\text { Os alunos acabam acessando redes sociais e outros site perdendo o } \\
\text { foco no conteúdo que está sendo proposto. }\end{array}$ & 8,9 & 48,2 & 26,8 & 17,9 \\
\hline $\begin{array}{l}\text { Estou confiante de que o uso da TIC torna minha prática docente } \\
\text { mais interessante para meus alunos. }\end{array}$ & 30,4 & 41,1 & 16,1 & 14,3 \\
\hline
\end{tabular}

Apesar de mais da metade discordar de que o uso do computador é uma distração, $48,2 \%$ concordam parcialmente que os alunos acessam redes sociais perdendo o foco no 
conteúdo disciplinar que está sendo proposto em aula. Aparece aqui uma contradição, entendida como uma incoerência entre ditos sucessivos, que permite especular a existência de um possível obstáculo de ordem didática epistemológica apontados em Schuhmacher (2014).

Entendemos serem estes resultados aplicáveis somente ao universo da amostra tendo em vista a possibilidade de erro amostral pelo baixo número de respondentes.

\subsection{Reinterpretando os dados a luz das competências digitais}

O modelo de competências docente proposto em Prendes (2010) sugere indicadores para cada tipo de atuação docente com diferentes níveis de proficiência. Para as atividades de docência são elencados 40 indicadores propostos em 6 níveis: D1, D2a, D2b, D2c, D3a e D3b. Foram analisados 18 indicadores. A estratégia utilizada na análise foi a de considerar como - não aplicável - indicadores que não foram atendidos no inquérito. Da lista de indicadores, passíveis de serem analisados a partir das questões do inquérito, entende-se que pelo menos $50 \%$ dos professores apresentam as competências sugeridas abaixo:

- D1: Conhece o papel das TIC na formação de licenciados; sabe as possibilidades e limitações das TIC como ferramentas de aprendizagem; é capaz de aprender de forma autônoma o uso de ferramentas e aplicações; conhece conceitos associados as TIC.

- D2a: Utiliza ferramentas TIC para produção de material didático; utiliza a TIC para difundir o material didático; usa os serviços de apoio à implementação das TIC fornecidos pela Universidade.

- D2b: Incentiva os alunos a utilizar as TIC como ferramentas de comunicação; utiliza a TIC em processos de tutoria.

$\mathrm{Na}$ análise os indicadores em que os professores não alcançam o propósito proposto na competência exigida pois auferem números inferiores a 50\% da amostra:

- D2a: Seleciona e usa estratégias e recursos em TIC adequados ao aprendizado do aluno; desenha atividades didáticas que incorporam os recursos em TIC.

- D2b: Utiliza diversas estratégias metodológicas com TIC; resolve necessidades de aprendizagem e/ou utiliza as TIC na avaliação da aprendizagem.

- D3b: Participa de projetos de inovação educativa com TIC; participa de atividades de formação relacionadas com as TIC; participa de espaços de reflexão presenciais para intercambio e experiências pedagógicas com TIC.

Ao analisarmos as respostas dos questionários frente aos indicadores para a docência propostos por Prendes (2010) percebe-se a fragmentariedade das competências desenvolvidas no grupo de amostra. Assim como o formador contempla premissas ele também deixa de atender indicadores que são inerentes a própria docência.

Vale a pena ressaltar que muitos dos indicadores não avaliados referem-se ao uso pedagógico-didático das TIC, grupos de experiência, estudo e pesquisa para qualificar a prática docente e a divulgação científica sobre as TIC no ensino.

\section{Considerações Finais}

Os resultados da pesquisa apontam um formador que se apresenta convicto do uso das TIC como um recurso instigante para sua prática. Suas motivações que redundam juntamente com as potencialidades nos porquês em utilizar as TIC apontam para um cenário bastante diversificado, mas ainda assim com conotações positivas e coerentes com o espaço de formação em que se situa. Quando interpelados sobre seus conhecimentos técnicos e pedagógicos os resultados apoiam a imagem de um professor com competências e habilidades para tais ações na prática docente. Entretanto, percebe- 
se também nos resultados a fragilidade e os baixos resultados da inserção curricular, para esta amostra de professores, em sua prática diária como um instrumento de mediação ou pesquisa.

As competências técnicas e pedagógicas apontadas pelos docentes não são efetivamente aplicadas na prática diária junto aos alunos no processo de ensinoaprendizagem. Corroboramos com Costa (2008) que afirma serem as concepções pedagógicas dos professores o fator que mais influencia o modo como as TIC são utilizadas pelos docentes professores nas suas aulas.

Consideramos que se espelhando em seu mentor, o professor formador, o graduando passa a entender as TIC como uma ferramenta de organização de sua aula, de comunicação ou para pesquisas na internet. Longe de acreditarmos que isso não seja válido, acreditamos ser pouco para o muito que a TIC tem a contribuir no processo de ensino.

\section{Referências bibliográficas}

CASTELLS, M. La dimensión cultural de Internet. Debates Culturales, Barcelona,2002. Disponível em: http://www.uoc.edu/culturaxxi/esp/articles Acesso em: 3 dez. 2015.

COSTA, F. A. Competências TIC: Estudo de implementação. Ministério da Educação - Gabinete de Estatística e Planeamento da Educação. Lisboa, 2008.

COUTINHO, C.; BOTTENTUIT JUNIOR, J. B. A complexidade e os modos de aprender na sociedade do conhecimento. In J. Ferreira \& A. R. Simões (Org.). Actas. do XV Colóquio AFIRSE: Complexidade: um novo paradigma para investigar e intervir em educação, Lisboa, 2008.

COUTINHO, Clara P. Metodologia de investigação em Ciências Sociais e Humanas: Teoria e Prática. Coimbra: Almedina, 2011. 412p.

GOMES, M. J.; AMANTE, L.; OLIVEIRA, I. Avaliação digital no Ensino Superior Português. Revista Linhas, Florianópolis, vol. 13, n. 02, 2012.

LEMOS, S.; PEDRO, N. Competências Digitais dos Docentes do Ensino Superior. Atas do II Congresso Internacional TIC e Educação, Lisboa, pp. 2839-2844, 2012.

LIVRO VERDE. Livro Verde para a Sociedade da Informação em Portugal. Missão para a Sociedade da Informação, Lisboa: Graforim, 1997.

CUNHA, Antônio, M. Plano de Atividades e Orçamento 2014. Universidade do Minho. Braga, Portugal, 2014.

PRENDES, E. M. P. Competencias TIC para la docencia en la Universidad Pública Española: Indicadores y propuestas para la definición de buenas prácticas: Programa de Estudio y Análisis. Informe del Proyecto EA2009-0133 de la Secretaría de Estado de Universidades e Investigación, 2010.

SCHUHMACHER, V. R. N. Limitações da Prática Docente no uso das Tecnologias da Informação e Comunicação. Florianópolis, SC: Universidade Federal de Santa Catarina, 2014. 346 p. Tese de Doutorado em Educação Científica e Tecnológica.

SCHUHMACHER, V. R. N.; PINHO ALVES, J. A TIC nos Projetos Político Pedagógicos das Licenciaturas. Revista Dynamis, Pós Graduação em Ensino de Ciências Naturais e Matemática. Blumenau, vol. 19, pp. 43-57, 2013.

SILVA, B. D.; ARAÚJO, A. M.; VENDRAMINI, C. M.; MARTINS, R. X.; PIOVEZAN, N. M.; PRATES, E.; ALMEIDA, L. S.; JOLY, M. C. R. A. Aplicação e uso de tecnologias digitais pelos professores do ensino superior no Brasil e em Portugal. Educação, Formação \& Tecnologias, Portugal, pp. 3-18, 2014.

UNESCO. Padrões de competência em TIC para professores. Organização das Nações Unidas para a Educação, a Ciência e a Cultura - UNESCO. Paris, França, 2008. 13p. 